\title{
De protagonistas a coadjuvantes: a ameaça "apache" na província de Nueva Viscaya (Norte do México, segunda metade do século XVIII)
}

Elisa Frïhauf Garcia*

Ortelli, Sara. Trama de una guerra conveniente: Nueva Vizcaya y la sombra de los apaches (1748-1790). México, D.F.: El Colegio de México, Centro de Estudios Históricos, 2007. 259 p.

A partir de rigorosa pesquisa documental, acompanhada de fina interpretação histórica, Sara Ortelli desmonta, passo a passo, alguns dos pressupostos estabelecidos sobre a história da província de Nueva Vizcaya, norte do México, durante a segunda metade do século XVIIII. Até então, as análises sobre o período estavam calcadas nas ameaças dos índios hostis à sociedade colonial, personificados nos "apaches", considerados o principal elemento para compreender a atmosfera de perigo e violência evidenciada na documentação.

Analisando uma vasta gama de fontes, localizadas em arquivos no

\footnotetext{
* Resenha recebida em setembro de 2007 e aprovada para publicação em novembro de 2007.

** Doutora em História pela UFF e pós-doutoranda em antropologia na Unicamp, bolsista do CNPq. E-mail: elisafg@terra.com.br.
} 
México e na Espanha, a autora busca perceber como surgiram e a quem serviam os informes sobre a iminência de um ataque dos índios. Inserindo a pesquisa na conjuntura específica da segunda metade do século XVIII, Ortelli aponta a aplicação das medidas bourbônicas, orientadas ao maior controle do poder central sobre áreas que até então gozavam de relativa autonomia, como um dos elementos explicativos para a irrupção não da violência em si, mas dos reclames generalizados sobre o perigo representado pelos "apaches" e pela sensação de insegurança vigente na província. Em sua argumentação, a aplicação dessas medidas ameaçaria o lugar ocupado por alguns dos principais membros das elites locais, que exerciam cargos relacionados à manutenção da segurança da região, especialmente nos fortes destinados ao controle da fronteira. Muitos dos seus membros, que alardeavam o perigo "apache", mantinham com esses índios relações bastante próximas, incluindo trocas comerciais, colaboração em atividades militares e laços pessoais. Assim, "a exaltação do perigo da guerra (tanto em seu aspecto real como potencial e imaginário) e a presença do inimigo (tanto em seu caráter de perigo efetivo, como mediante sua construção como perigo iminente) serviram para sustentar interesses, justificar situações e defender privilégios" (p. 51).

Além desses agentes, beneficiários diretos da manutenção da atmosfera de violência, surgem outros grupos e as relações sociais se complexificam, à proporção que uma leitura atenta dos documentos vai descortinando novos sujeitos, estratégias diferenciadas e incertezas no seio da própria administração. Os administradores coloniais, especialmente os designados em função da aplicação das medidas bourbônicas e, em alguns momentos, desconfiados que os alardes sobre a insegurança poderiam estar sendo usados como subterfúgios, organizaram expedições para averiguar a real dimensão do perigo "apache". Nessas expedições, foram raros os momentos em que de fato se depararam com "o inimigo", embora a simples possibilidade disto acontecer era suficiente para encher de temor os seus integrantes, devido aos rumores sobre a ferocidade dos “apaches” e seus hábitos supostamente antropofágicos.

Os funcionários reais, além de divisarem um território onde as ameaças não eram onipresentes, mas meramente circunstanciais, quando se deparavam com bandos que praticavam ataques orientados ao roubo de rebanhos, não encontravam exatamente os "apaches", mas grupos 
heterogêneos, compostos por indivíduos de origens diversas. Dentre eles havia espanhóis, italianos, membros das "castas", africanos e seus descendentes, além de índios fugidos, temporária ou definitivamente, dos pueblos.

Os roubos de animais também eram praticados por outros grupos, denominados especificamente como abigeatários. Para a autora, longe de ser uma prática ocasional, o abigeato era uma atividade a qual alguns grupos se dedicaram ao longo de anos e de gerações sucessivas. Seus membros muitas vezes estavam interligados por redes de parentesco e laços pessoais, tanto verticais quanto horizontais, que viabilizavam a continuidade da prática e certa imunidade diante de possíveis condenações pelos roubos. Ao constatar que, uma vez aprisionados, esses homens não eram condenados pela justiça, Ortelli demonstra as suas relações com integrantes das famílias de elite da região, que os vinculavam à sociedade local e transformavam suas práticas em algo estrutural na província. Novamente a autora discorda frontalmente com interpretações consolidadas na historiografia, que imputavam tais roubos a situações de instabilidade política e econômica ou à "desordem" social por ocasião da independência.
As expedições de reconhecimento e a maior percepção sobre a realidade local trouxeram aos funcionários reais uma conclusão surpreendente: as ameaças na região não provinham de grupos localizados fora da sociedade colonial, como no caso dos "apaches", mas eram formadas pelos habitantes das vilas e povoados da província. Por outro lado, a complexa teia de interesses por trás dos roubos e as dificuldades encontradas para efetivamente visualizar quem eram afinal os responsáveis pelos mesmos, assim como para puni-los uma vez descobertos, demonstraram também os limites para a aplicação das medidas formuladas na corte. Ao tentarem aplicar as medidas bourbônicas, os agentes do rei encontraram uma sociedade com uma dinâmica própria, articulada de acordo com privilégios adquiridos, cujos beneficiários não seriam facilmente alijados e/ou remanejados para satisfazer os macro-interesses geopolíticos, administrativos e econômicos do Império espanhol.

Os "apaches" propriamente ditos, apesar de raramente divisados pelos funcionários reais, participavam da cadeia de roubos como receptadores dos gados e dificilmente como perpetradores dos assaltos aos rebanhos. Em troca do gado, ofereciam peles e uma mercadoria importante 
para o desempenho das atividades dos bandos: roupa "tipicamente apache". Munidos dessas vestimentas e com o rosto pintando com carvão, os integrantes dos bandos praticavam os assaltos com a intenção de que fossem atribuídos aos "apaches". O disfarce tinha ainda outra função: dificultar a sua identificação, pois muitos deles faziam parte da sociedade colonial e temiam ser reconhecidos enquanto praticavam tais atividades.

Ao abordar os índios aldeados e sua interação com os demais segmentos da sociedade colonial, a autora enfrenta questões importantes e atuais nos estudos sobre a temática. Analisando a sua mobilidade, inclusive a participação em atividades consideradas ilícitas, demonstra como a existência de duas repúblicas distintas, de espanhóis e de índios, era uma representação idealizada que pouco condizia com a realidade da província. A despeito disto, tal representação continuava a ser usada pelos espanhóis para perceber a sociedade em que viviam e orientava a formulação de medidas que buscavam intervir na mesma. Os aldeados, por sua vez, apesar das representações idealizadas que os circunscreviam ao espaço dos pueblos e controlados pelas ordens religiosas, possuíam amplas relações sociais e econômicas fora dos aldeamentos e a opção por ir e vir dos mesmos era uma possibilidade manejada por muitos deles. Além de não estarem rigidamente apartados da “república de espanhóis”, mantinham ainda relações com os índios não inseridos na sociedade neovizcaína, como os próprios "apaches". Tais relações foram interpretadas pelos funcionários reais como uma desagregação da "república de índios", principalmente após a expulsão dos jesuítas dos domínios americanos. Neste ponto, Ortelli novamente destaca o descompasso entre a representação do mundo colonial e seu funcionamento efetivo, pois essas relações eram anteriores ao estabelecimento dos espanhóis na região e se mantiveram ao longo do tempo, ainda que reformuladas e ressignificadas.

Como demonstrado também por estudos em várias regiões da América portuguesa, as relações dos diferentes grupos indígenas entre si e suas interações com a sociedade colonial eram dinâmicas e orientadas, na medida do possível, pelas suas próprias demandas. Assim, apesar das tentativas dos colonizadores de classificar de maneira estanque as populações indígenas a partir dos diferentes mecanismos de sua inserção na sociedade colonial, suas relações eram marcadas pela fluidez, variando de acordo com a reformulação de suas demandas diante das oportunidades 
e desafios enfrentados em diversas conjunturas. ${ }^{1}$

Outro aspecto importante levantado pela autora é a interpretação vigente em certa historiografia que considerava os ataques, entendidos como protagonizados pelos índios, como uma manifestação de resistência à sociedade colonial. De modo um pouco genérico, essa resistência era entendida como ataques deliberados contra o "sistema colonial", destinados a miná-lo, expulsando os espanhóis e retomando o domínio sobre o território que teria sido dos índios antes da conquista. Longe disso, os roubos, assim como as eventuais violências deles decorrentes, eram um elemento estrutural daquela província, cujos envolvidos pertenciam a diferentes estratos sociais. Assim, não eram iniciativas contra o "sistema colonial”, mas existiam em função do mesmo. Esta questão é demonstrada a partir da convergência entre os períodos de maior incidência de roubos de rebanhos e os picos da atividade mineradora. Dependente do uso de animais, especialmente mulas utilizadas no processo necessário para a extração da prata e para o transporte, a mineração era usualmente abastecida com animais roubados. Os roubos, portanto, tinham um destino certo: compradores que necessitavam dos animais para assegurar o funcionamento da mineração e, no limite, a própria manutenção da lucratividade da região para os colonos e para o Império espanhol.

Após descortinar esta gama de agentes interessados, por motivos diversos, na manutenção da situação de guerra, real ou fictícia, na província, Ortelli conclui que muito pouco deste contexto estava diretamente vinculado aos "apaches", pois a violência daquela sociedade "respondia às ações de grupos de atribuição étnica heterogênea e que a alusão aos 'apaches' era, na maior parte dos casos, um lugar comum que permitia encobrir um fenômeno que não provinha do exterior do sistema” (p. 209).

\footnotetext{
${ }^{1}$ Sobre o tema veja-se, dentre outros: Maria Regina Celestino de Almeida, Metamorfoses indigenas: identidade e cultura nas aldeias coloniais do Rio de Janeiro, Rio de Janeiro, Arquivo Nacional, 2003; Elisa Frühauf Garcia, As diversas formas de ser indio: políticas indígenas e políticas indigenistas no extremo sul da América portuguesa, Rio de Janeiro, Arquivo Nacional (no prelo); Patrícia Sampaio, Espelhos partidos: etnia, legislação e desigualdade na Colônia: sertões do Grão-Pará, c.1755-c.1823, tese de doutorado apresentada ao Programa de Pós-Graduação em História da UFF, 2001; Almir Diniz de Carvalho Junior, Índios cristãos: a conversão dos gentios na Amazônia portuguesa (1653-1769), tese de doutorado apresentada ao Programa de Pós-Graduação em História da Unicamp, 2005; Márcia Malheiros, "Homens da Fronteira": Índios e Capuchinhos na ocupação dos Sertões do Leste, do Paraíba ou Goytacazes, séculos XVIII $e X I X$, tese de doutorado apresentada ao Programa de Pós-Graduação em História da UFF, 2008 .
} 
Assim, a investigação não está tanto orientada em aprofundar quem de fato eles eram, mas como essa ameaça surge, e posteriormente arrefece, em contextos específicos. Neste sentido, a autora demonstra com propriedade que essa ameaça não se originou de uma alteração nas relações sociais até então vigentes na província. Pelo contrário, foi a possibilidade de uma mudança, gerada pelas tentativas de aplicação das medidas bourbônicas, que fez surgir o perigo "apache". Nessa conjuntura, o termo foi reformulado e o seu significado extrapolava uma mera atribuição étnica, pois passou a simbolizar um determinado modo de vida, identificado como "apache", porém não restrito aos índios. Assim, tal como vários etnônimos em diferentes partes das Américas, aquele era um atributo genérico e maleável, cujos significados transformavam-se ao longo do tempo e cujos usos variavam de acordo com os interesses em questão. Devem, portanto, ser problematizados e entendidos como uma construção colonial.

De um lugar predominante na historiografia sobre Nueva Vizcaya, os "apaches", na realidade desvelada por Ortelli, aparecem como apenas mais um dos grupos envolvidos nos roubos de gado, muitas vezes desempenhando a função de coadjuvantes. Fruto da tese de doutorado da autora, defendida no Centro de Estudios Históricos do Colegio de México em 2003 e vencedora no mesmo ano do prêmio de Melhor Tese de Doutorado em Ciências Sociais e Humanidades outorgado pela Academia Mexicana de Ciencias, Trama de una guerra conveniente merece ser lido com atenção pelo público brasileiro, não apenas pela excelência do trabalho, mas também pela semelhança de muitas situações investigadas com as enfrentadas em nossa historiografia. Dentre elas, principalmente, a dinâmica fronteiriça e a latência de ataques dos índios hostis, característica da América portuguesa em vários momentos, não apenas em relação aos limites com as possessões de outros Estados, mas também no seu interior, especialmente nas regiões vagamente denominadas de sertão. ${ }^{2}$

Nestes casos, o livro de Ortelli sugere que qualquer análise sobre os

\footnotetext{
${ }^{2}$ Sobre os significados do termo sertão na sociedade colonial veja-se: A.J.R. Russel-Wood, "Fronteiras do Brasil colonial", Oceanos, Lisboa, Comissão Nacional para as Comemorações dos Descobrimentos Portugueses, n.40, out.-dez. 1999. Para diferentes abordagens sobre as populações indígenas que habitavam as regiões denominadas como sertão veja-se, dentre outros: Nadia Farage, As muralhas dos sertões: os povos indigenas e a colonização do Rio Branco, Rio de Janeiro, Paz e Terra/Anpocs, 1991; Glória Kok, O sertão itinerante: expedições da capitania de São Paulo no século XVIII, São Paulo, Hucitec/Fapesp, 2004; Maria Leônia Chaves de Resende e Hal Langfur, "Minas Gerais indígena: a resistência dos índios nos sertões e nas vilas de El-Rei”, Tempo, vol.12, n.23, jul-dez.2007.
} 
grupos nativos deve ser acompanhada de um estudo criterioso das fontes e das dinâmicas locais. Tal como no caso de Nueva Vizcaya, também no Brasil muitos eram beneficiários dos perigos, reais e imaginários, atribuídos à "ferocidade" dos índios. Se, como apontou Beatriz Perrone-Moisés, o "inimigo" indígena foi muitas vezes construído pelos colonos que visavam legitimar expedições de apresamento, ${ }^{3}$ nessas construções também estavam subsu- midos outros interesses que, através da propagação do perigo latente, apresentavam determinados grupos locais como imprescindíveis à manutenção de certa ordem. Tal ordem era, em muitas situações, a preservação de um status quo do qual os principais beneficiários eram esses mesmos grupos, na medida em que utilizavam o "perigo indígena" para manter e/ ou adquirir posições e privilégios na sociedade local.

\footnotetext{
${ }^{3}$ Beatriz Perrone-Moisés, "Índios livres e índios escravos: os princípios da legislação indigenista do período colonial (séculos XVI a XVIII), in: Manuel Carneiro da Cunha, História dos indios no Brasil, São Paulo, Companhia das Letras/Secretaria Municipal de Cultura/Fapesp, 1992, p.125.
} 